\title{
Hydrological processes of glacier and snow melting and runoff in the Urumqi River source region, eastern Tianshan Mountains, China
}

\author{
SUN Meiping ${ }^{1}$, YAO Xiaojun ${ }^{1}$, LI Zhongqin ${ }^{2}$, ZHANG Mingjun ${ }^{1}$
}

1. College of Geography and Environment Science, Northwest Normal University, Lanzhou 730070, China;

2. State Key Laboratory of Cryosphere Sciences, Cold and Arid Region Environment and Engineering Research Institute, CAS, Lanzhou 730000, China

\begin{abstract}
Hydrological processes were compared, with and without the influence of precipitation on discharge, to identify the differences between glacierized and non-glacierized catchments in the Urumqi River source region, on the northern slope of the eastern Tianshan Mountains, during the melting season (May-September) in 2011. The study was based on hydrological data observed at 10-min intervals, meteorological data observed at 15-min intervals, and glacier melting and snow observations from the Empty Cirque, Zongkong, and Urumqi Glacier No.1 gauging stations. The results indicated that the discharge differed markedly among the three gauging stations. The daily discharge was more than the nightly discharge at the Glacier No.1 gauging station, which contrasted with the patterns observed at the Zongkong and Empty Cirque gauging stations. There was a clear daily variation in the discharge at the three gauging stations, with differences in the magnitude and duration of the peak discharge. When precipitation was not considered, the time-lags between the maximum discharge and the highest temperature were 1-3 h, 10-16 h, and 5-11 h at the Glacier No.1, Empty Cirque, and Zongkong gauging stations, respectively. When precipitation was taken into consideration, the corresponding time-lags were $0-1 \mathrm{~h}, 13 \mathrm{~h}$, and $6-7 \mathrm{~h}$, respectively. Therefore, the duration from the generation of discharge to confluence was the shortest in the glacierized catchment and the longest in the catchment where was mainly covered by snow. It was also shown that the hydrological process from the generation of discharge to confluence shortened when precipitation was considered. The factors influencing changes in the discharge among the three gauging stations were different. For Glacier No.1 station, the discharge was mainly controlled by heat conditions in the glacierized region, and the discharge displayed an accelerated growth when the temperature exceeded $5^{\circ} \mathrm{C}$ in the melt season. It was found that the englacial and subglacial drainage channel of Glacier No.1 had become simpler during the past 20 years. Its weaker retardance and storage of glacier melting water resulted in rapid discharge confluence. It was also shown that the discharge curve and the
\end{abstract}

Received: 2014-08-29 Accepted: 2014-09-22

Foundation: National Science and Technology Support Plan Projects, No.2012BAC19B07; Scientific Research Project of Higher Learning Institution in Gansu Province, No.2013A-018; Project of Scientific Ability Promoting of Young Teachers of Northwest Normal University, No.NWNU- LKQN-12-20

Author: Sun Meiping (1981-), PhD and Associate Professor, specialized in the research of hydrological processes and the climate change impact assessment. E-mail: sunmeiping1982@163.com 
time-lag between the maximum discharge and the highest temperature could be used to reveal the evolution of the drainage system and the process of glacier and snow melting at different levels of glacier coverage.

Keywords: glacier and snow melting; runoff generation and confluence; hydrological process; Urumqi River source region; Tianshan Mountains

\section{Introduction}

Glacier and snow melting and their hydrological processes are not only the key hydrological research issues in cold regions, but also are important to determine the hydrologic parameters in glacial runoff simulations (Yang et al., 2000; Hock, 2005; Kaser et al., 2010). The meltwater produced in snow and glacier fields is mainly affected by the underlying surface, which leads to differences in its storage and flow process (Hock and Hooke, 1993; Zhang et al., 2007). So far, there are only two main methods used to study the runoff generation and confluence processes: dye tracers and the statistical analysis of hydrological and meteorological data (Hasnain et al., 2001; Schuler et al., 2004; Singh et al., 2006; Liu and Liu, 2012; Gao et al., 2013; Yin et al., 2014). By conducting a series of tracer tests during the ablation season in 2000, Schuler et al. (2004) investigated the hydraulic conditions of a subglacial drainage system, the conflux speed, meltwater subglacial process, and its arrival time to a hydrologic section. Using the same method, Hasnain et al. (2001) studied the Dokriani Glacier in India, and confirmed that the largest meltwater discharge occurred in the middle of July and August. And major changes in meltwater discharge were related to the development of a glacier drainage system during the ablation period. Using the statistical analysis method, Singh et al. (2006) studied the lag effect between runoff generation and confluence, and hydrological processes associated with the Dokriani and Gangotri glaciers on the southern slopes of the Himalayas. They found that the time-lags between the maximum discharge and the highest temperature were 3-6 $\mathrm{h}$ and 4-7.5 $\mathrm{h}$ in the periods of 1996-1998 and 2000-2003, respectively, although they had gradually decreased with glacier melting.

Our domestic research on the drainage system characteristics in the ablation area of glacier began in the late 1980s. Kang Ersi (1991) conducted a salt tracer experiment at Urumqi Glacier No.1, and found that the time required for glacier meltwater arriving at the gauging station ranged from $7 \mathrm{~min}$ to $2 \mathrm{~h}$ at seven injection points. This suggested that the englacial and subglacial drainage channels of Glacier No.1 were simple. With climate warming, the Urumqi Glacier No.1 had undergone an accelerated retreat (Li et al., 2011), and was divided into two glaciers in 1993. Its area, length, mass balance and equilibrium line altitude (ELA) also changed dramatically. For example, the ELA increased from $4042 \mathrm{~m}$ (1959-1996) to 4106 m (1997-2008) (Sun et al., 2013). An increase in the ELA will inevitably lead to reductions in the firn and snow areas, decreases in snow thickness, as well as changes in the meltwater confluence process, which subsequently affect glacier meltwater runoff characteristics. There is an urgent need to determine whether the englacial and subglacial drainage systems of Glacier No.1 have undergone significant changes in the past 20 years, and to identify the discharge variation characteristics of the other two gauging stations in the Urumqi River source region. Based on the observed hydrological and meteorological data, glacier melting and snow observations in the Urumqi River source region, we investigated 
the differences in the hydrological processes between glacierized and non-glacierized catchments in the ablation season (May-September) in 2011. The aim is to better understand the physical mechanisms of hydrological elements in the Urumqi River source region on the micro-scale, and to provide a reference for glacier runoff simulations and the study of glacier dynamic processes.

\section{Study area}

The Urumqi River source region is located on the northern side of the eastern Tianshan Mountains, with the highest elevation of 4,479 m (Tengger Mountain II). In the region above $3600 \mathrm{~m}$, the average daily temperature is below $0^{\circ} \mathrm{C}$ and the average annual precipitation is $337.5 \mathrm{~mm}$. Tianshan Glaciological Station, Chinese Academy of Sciences (TGS CAS) established three gauging stations and meteorological observational stations in the late 1950s (Figure 1), to conduct a long-term glacial, hydrological and meteorological monitoring in the Urumqi River source region. Glacier No.1 gauging station is used to monitor Glacier No.1 meltwater runoff. It is located $300 \mathrm{~m}$ downstream of the glacier terminus, at an altitude of $3693 \mathrm{~m}$, and covers a drainage area of $3.34 \mathrm{~km}^{2}$, of which nearly half is glacierized. The catchment monitored by the Empty Cirque (kongbingdou) gauging station is a small non-glacierized but barren rocked. The cirque is $2 \mathrm{~km}$ long and $1.5 \mathrm{~km}$ wide, and is located on the northern side of Glacier No.1, with headwalls surrounded and a gentle bottom. The main role of the Empty Cirque gauging station is the monitoring of snowmelt runoff, and it is located in the drainage channel of the cirque, with a drainage area of $1.68 \mathrm{~km}^{2}$. The Zongkong gauging station is located at the junction of Daxigou and Luobudaogou, and is used to monitor the precipitation, as well as total meltwater runoff from seven glaciers and snow on the surrounding mountains. Its drainage area is $28.90 \mathrm{~km}^{2}$, of which $19.4 \%$ being

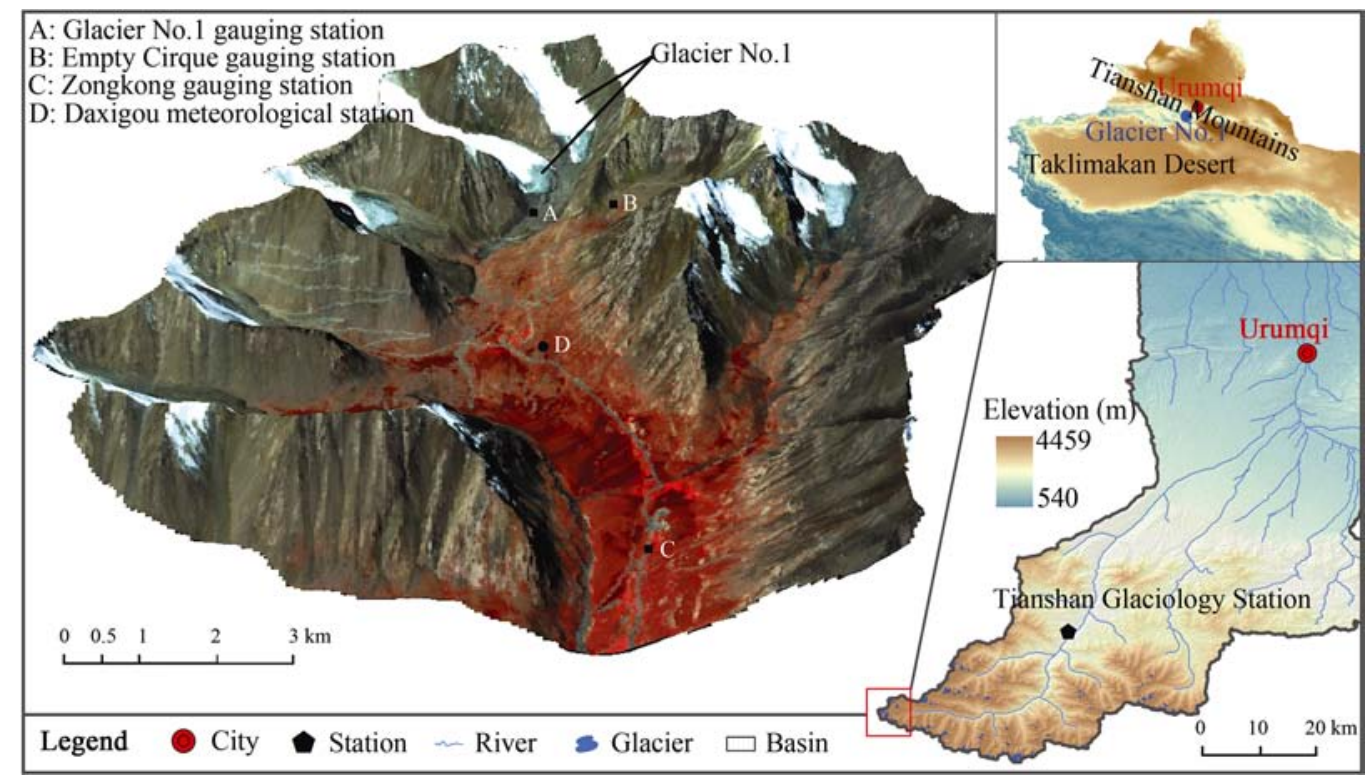

Figure 1 The location of Urumqi River source region and the glacier distribution (the base map is the SPOT 5 image acquired on September 7, 2005) 
covered by glaciers. The remaining area is the exposed bedrock and periglacial geomorphology, including the extensive development of roche moutonnée and drumlins.

\section{Data and methods}

\subsection{Data}

Hydro-meteorological data was available from the TGS CAS. The water level was recorded every 10 minutes using a HOBO limnigraph (Onset: Bourne, MA, USA) at all three gauging stations over the whole ablation season (May-September) in 2011. The measured water level records were converted to discharges based on rating curves. Meteorological data, including temperature and precipitation every 15 minutes were recorded by automatic weather stations located near the hydrometric stations.

\subsection{Methods}

(1) Considering the influence of precipitation on discharge

Using the method proposed by Singh et al. (2006), we selected a continuous period of sunny days, with no more than $2 \mathrm{~mm}$ precipitation, from May to September in 2011, and recorded the time-lag between the maximum discharge and the highest temperature.

(2) Not considering the influence of precipitation on discharge

Using the method proposed by Jobard and Dzikowski (2006), one day was used as a time window, with hourly discharge and temperature data used for cross correlation, and the time-lag between runoff and temperature variation was calculated as follows:

$$
\begin{gathered}
r_{x y}(k)=\frac{C_{x y}(k)}{\sigma_{x} \sigma_{y}} \\
C_{x y}(k)=\frac{1}{n} \sum_{i=1}^{n}\left(x_{i+k}-\mu_{x}\right)\left(y_{i}-\mu_{y}\right) \\
\sigma_{x}=\sqrt{\frac{n \sum x^{2}-\left(\sum x\right)^{2}}{n(n-1)}} \\
\sigma_{y}=\sqrt{\frac{n \sum y^{2}-\left(\sum y\right)^{2}}{n(n-1)}}
\end{gathered}
$$

where $x$ and $y$ are the temperature and discharge time-series data, respectively; $\sigma_{x}$ and $\sigma_{y}$ are the mean square deviations of series $x$ and $y$, respectively; $\mu_{x}$ and $\mu_{\mathrm{y}}$ are the means of series $x$ and $y$, respectively; $C_{x y}(k)$ is the cross-covariance matrix between series $x$ and $y$ at time-lag $k$; $n$ refers to the samples from one day, here the value is 24 ; and $r_{x y}(k)$ is the cross-correlation function between series $x$ and $y$ at time-lag $k$ (values of $0,1,2, \ldots, 20$, assuming that the lag is not more than $20 \mathrm{~h}$ ), it can vary between -1 and 1 . For a daily data series, the $k$ value, which corresponds to the maximum cross correlation function $r_{x y}(k)$, is the time-lag between the air temperature and the daily discharge (hereafter termed the $Q-T$ time lag). 


\section{Results}

\subsection{The daily variation of glacier and snow melting}

Figure 2 shows the daytime (09:00-20:00) and nighttime (21:00-08:00) discharges and the mean diurnal variation in discharge during the ablation season at the three gauging stations (Urumqi Glacier No.1, Empty Cirque, and Zongkong). The results showed that the discharge differed markedly among the three gauging stations. The daily discharge was more than the nighttime discharge at Glacier No.1 gauging station, which contrasted with the results for the Zongkong and Empty Cirque gauging stations. Furthermore, the variation in daily and nighttime discharges from June to August was greater than that in May and September, and the largest differences occurred in June and July. The discharge at the three gauging stations displayed an obvious daily variation from 01:00 to 24:00, with an initial reduction, then an increase followed by a further decrease. The time that the maximum discharges occurred were 14:00-18:00, 23:00-01:00, and 21:00-01:00, and the minimum discharges occurred at 08:00-10:00, 13:00-15:00, and 13:00-18:00 at the Glacier No.1, Empty Cirque, and Zongkong gauging stations, respectively. The months in which the maximum and minimum discharges occurred were also different, with the maximum discharges at the Glacier No.1 and Empty Cirque gauging stations occurring in July, but at Zongkong gauging station the maximum appeared in June. The minimum discharges at all three gauging stations occurred in May (N.B., in Figure 2, no discharge variation is shown for May at the Glacier No.1 and Empty Cirque gauging stations because the data was incomplete). Table 1 shows that the time from maximum to minimum discharge is the shortest at Glacier No.1 gauging station,
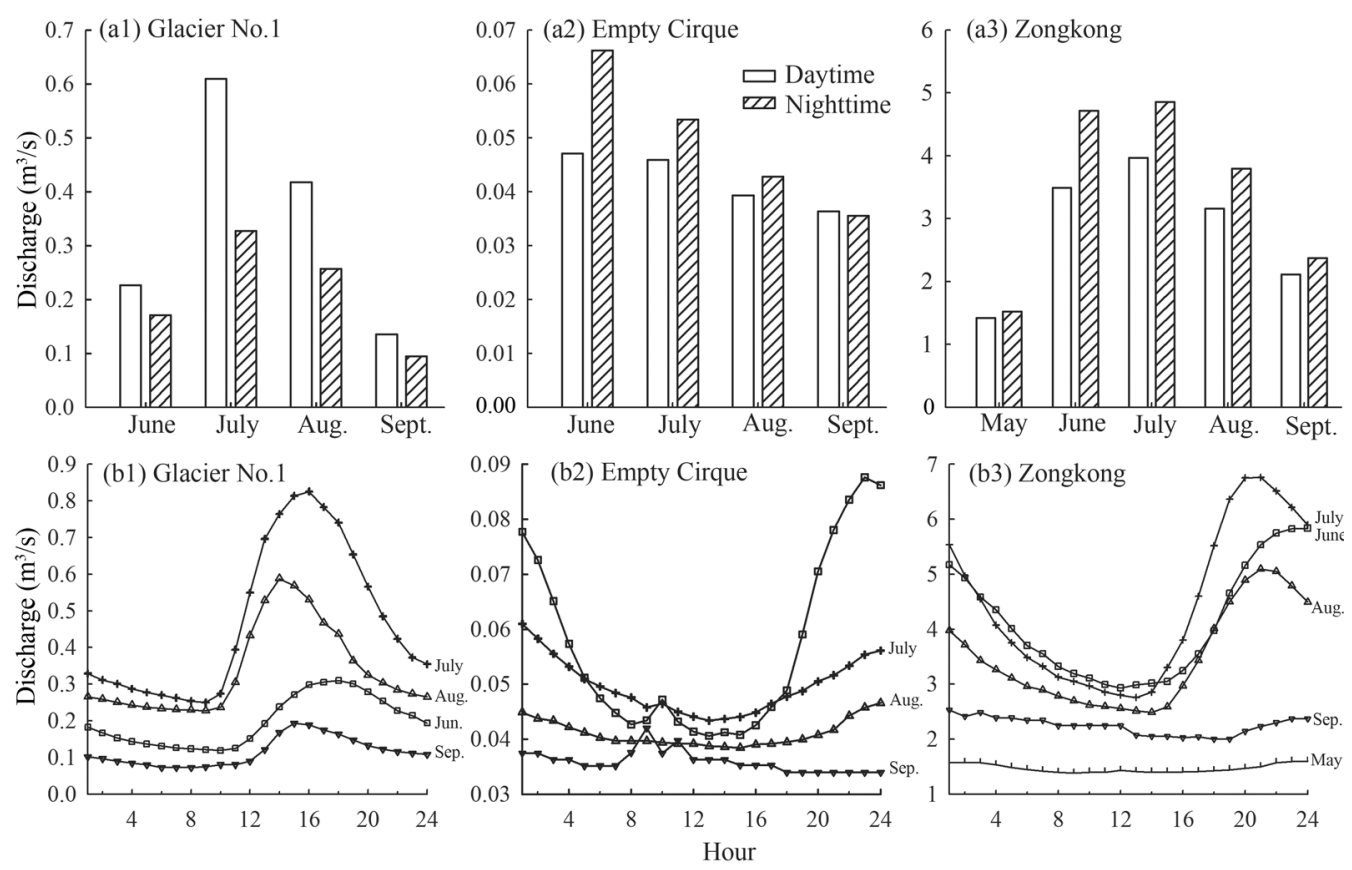

Figure 2 The comparison of daytime (09:00-20:00) and nighttime (21:00-08:00) discharges and mean diurnal variation in discharge during the ablation season at the three gauging stations 
Table 1 The time and its duration when daily maximum and minimum discharges occur at the three gauging stations

\begin{tabular}{|c|c|c|c|c|}
\hline Gauging station & Months & $\begin{array}{c}\text { Minimum } \\
\text { discharge } \\
\text { occurrence time }\end{array}$ & $\begin{array}{l}\text { Maximum discharge } \\
\text { occurrence time }\end{array}$ & $\begin{array}{l}\text { Duration from minimum } \\
\text { discharge to maximum dis- } \\
\text { charge }(\mathrm{h})\end{array}$ \\
\hline \multirow{4}{*}{ Glacier No.1 } & 6 & $10: 00$ & $18: 00$ & 8 \\
\hline & 7 & 09:00 & $16: 00$ & 7 \\
\hline & 8 & 09:00 & $14: 00$ & 5 \\
\hline & 9 & 08:00 & $15: 00$ & 7 \\
\hline \multirow{3}{*}{ Empty Cirque } & 6 & $15: 00$ & 23:00 & 8 \\
\hline & 7 & $13: 00$ & 01:00 & 12 \\
\hline & 8 & $15: 00$ & $24: 00$ & 9 \\
\hline \multirow{5}{*}{ Zongkong } & 5 & $14: 00$ & 23:00 & 9 \\
\hline & 6 & $15: 00$ & 23:00 & 8 \\
\hline & 7 & $13: 00$ & 21:00 & 8 \\
\hline & 8 & $14: 00$ & 21:00 & 7 \\
\hline & 9 & $18: 00$ & 01:00 & 7 \\
\hline
\end{tabular}

at only 5-8 h. The second shortest time was at Empty Cirque gauging station, where the time interval was 7-8 h, and the longest time was at Zongkong gauging station, especially in July, where $12 \mathrm{~h}$ were required. In addition, in the strong ablation period of July and August, the time from maximum to minimum discharge was shortened to about 1-3 h compared with the beginning (May) and end (September) of the ablation period at the three gauging stations. Fountain and Walder (1998) found that the flow velocity in the glacial area was often faster than in the firn and snow areas. As described in section 2, the underlying surface at the three gauging stations was significantly different. With the melting of Glacier No.1, there were reductions in the glacier thickness, and the size and water retention capacity of the snow and firn area, thus the average transmission speed of meltwater on the glacier increased. This explains why the time from maximum to minimum discharge at Glacier No.1 gauging station was less than at the other two gauging stations.

\subsection{Lag effects from meltwater to confluence}

To further clarify the relationship between discharge and meteorology in the Urumqi River source region, we explained glacier melt runoff, snowmelt runoff, and high mountain runoff from two perspectives: with and without considering the influence of precipitation.

\subsubsection{Glacier meltwater runoff}

Glacier meltwater runoff refers to the runoff of Glacier No.1. Figure 3 shows the diurnal variation of hourly discharge and temperature in clear weather days from June to September in 2011 (N.B., we did not analyze May in Figure 3 because there was no period of three consecutive days without rain). Figure 3 showed that, when excluding the influence of precipitation, the discharge curve was relatively smooth for 6-8 months, but linear-stage fluctuations were observed in September. To some extent, this reflected the evolution of the river 

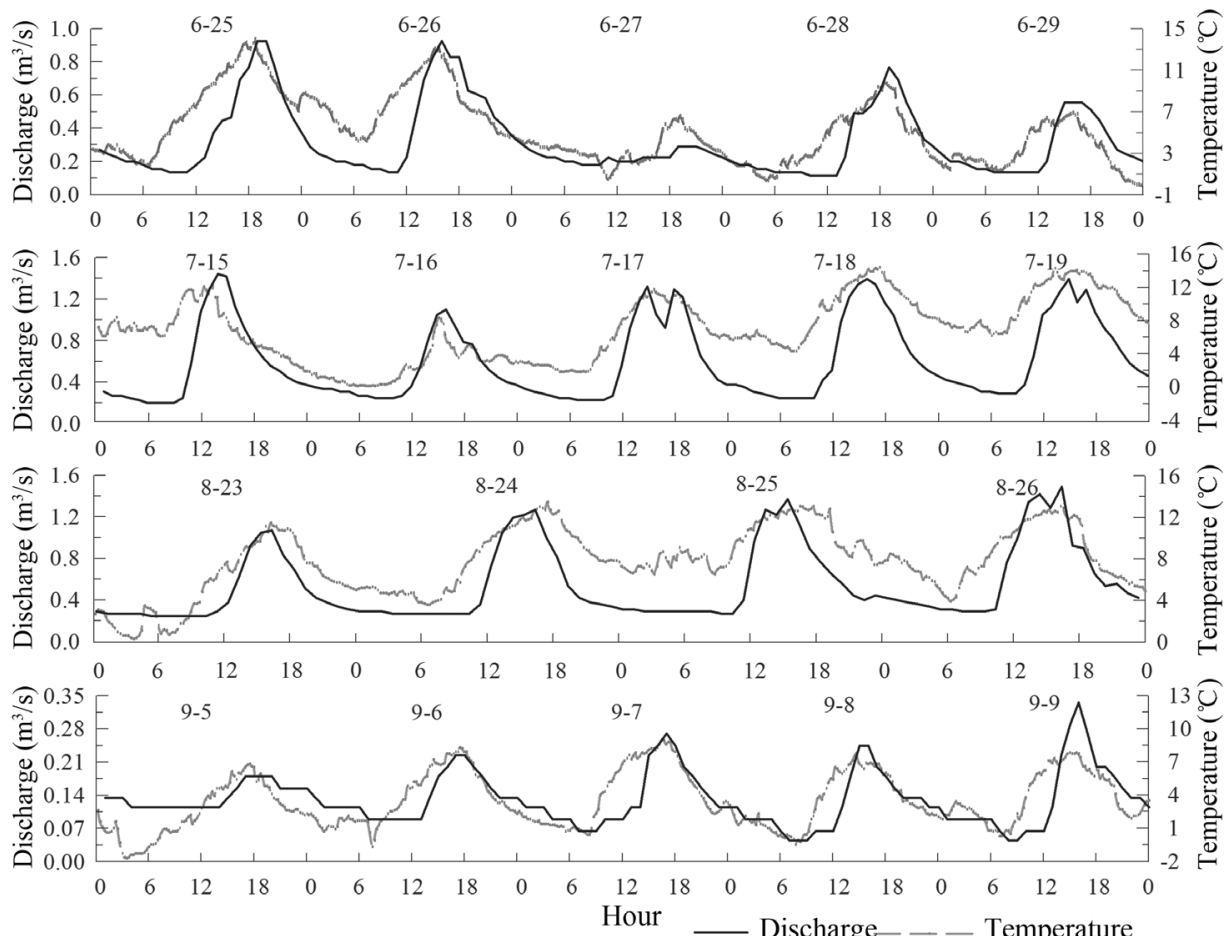

Figure 3 Diurnal variation in discharge (solid line) and temperature (dashed line) of Glacier No.1 gauging station in the clear weather days

system in the area of the drainage basin monitored by Glacier No.1 gauging station. Hock and Hooke (1993) reported that the meltwater confluence time-lag was strongly affected by the size of the snow area and the strength of the drainage system. At the beginning of the ablation period, the snow on the surface of Glacier No.1 began to melt first, and heat was transferred downwards through the pores that emerged, resulting in the areas between the pores also gradually melting (Figure 4a). As the temperature increased melting strengthened, and the melting zone gradually migrated from the end of the glacier tongue to higher altitudes, reducing the snow area and the thickness of snow cover; thus, a large area of the glacier began to melt. Field observations revealed that the ice surface of Glacier No.1 was completely exposed in the region below 4,055 $\mathrm{m}$ (east branch) and 4,120 $\mathrm{m}$ (west branch) on August 2, 2011. At this point the development of the drainage system in the glaciated area was perfect, the drainage path in the firn area and glacier gradually became stable (Figure 4b), the flow speed of meltwater and liquid precipitation was accelerated (Figure 4c), the time that meltwater from runoff generation to confluence was shortened, and therefore the discharge curves became continuous and smooth. At the end of the ablation period, temperature decreased, and the melting strength of the glacier and snow was reduced accordingly. Discharge therefore decreased and the drainage channel of the watershed underlying the surface became narrow or froze, making meltwater intermittent. Under these conditions, the discharge curve at Glacier No.1 gauging station was no longer smooth.

From the discharge and temperature recorded at Glacier No.1 station, when precipitation was not considered, the $Q-T$ time lag was $1-3 \mathrm{~h}$ in June and September. In July of the middle 


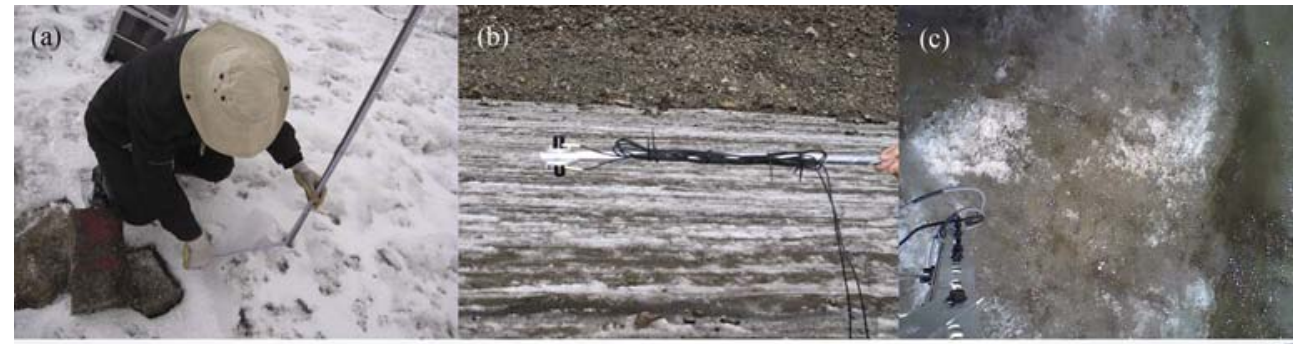

(d)

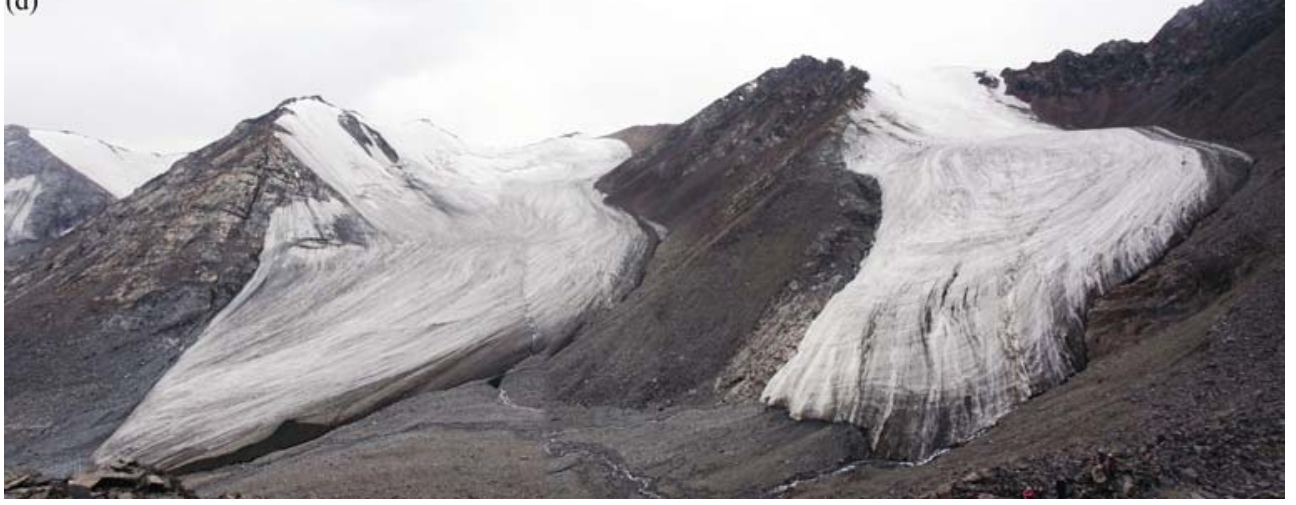

Figure 4 Ablation stacks observation (a), radiation observation (b) and surface ablation observation of east branch (c); the full view of Glacier No.1 (d) on August 2, 2011 (Photographs provided by Wang Wenbin and Jin Shuang)

ablation period, the maximum discharge and the highest temperature occurred almost simultaneously. In August of the strong ablation period, the diurnal variation of the discharge peak was stronger than the diurnal variation of the temperature peak. However, the discharge peak should occur within a few hours of the maximum melting (i.e., the highest temperature). This abnormal phenomenon in August may be related to the high cryoconite content on the glacier surface. Some studies have indicated that the accumulation of impurities, such as aerosol dust and glacial till, on the glacier surface would increase as the glacier melts. A large amount of accumulation of cryoconite would reduce the glacier surface albedo and improve the glacier's ability to absorb radiation, thus enhancing glacier melting (Takeuchi and Li, 2008; Xu et al., 2013). Figures 4c and 4d show that the surface pollution of Glacier No.1 was very serious in August, which could have accelerated melting of the glacier surface at a certain temperature and generated an early discharge peak.

When precipitation was considered, the $Q-T$ time lag of the ablation period in 2011 was about $1 \mathrm{~h}$ shorter than when precipitation was not considered. A small part of the $Q-T$ time lag was distributed in the 4-18 h before the mid-June (Figure 5), which reflected the lack of development of the englacial and subglacial drainage channel in the initial stage of melting, and therefore a long time was required from runoff generation to confluence. In July and August, the $Q-T$ time lag was mostly 0 h; i.e., the maximum discharge and the highest temperature occurred at the same time. This indicated that for these two months, the coexistence of precipitation and high air temperatures allowed the englacial and subglacial drainage channel to develop, and therefore the glacier melting rate and the diurnal maximum cross-correlation coefficient reached a maximum. There was also an inverse relationship between the variation in the diurnal maximum cross-correlation coefficient and changes in 
precipitation; i.e., on a same day when precipitation was large (or the next day), the daily maximum cross-correlation coefficient was small. This further indicated that, although precipitation could shorten the $Q-T$ time lag to some extent, the key factor affecting the discharge recorded at Glacier No.1 gauging station was temperature. This was consistent with the results of studies that applied the wavelet variance methods of Sun et al. (2012a). In contrast, Kang (1991) found that the englacial and subglacial drainage channel in Glacier No.1 became simpler during the past 20 years, and its weaker retardance and storage of glacier meltwater resulted in a quick discharge confluence.

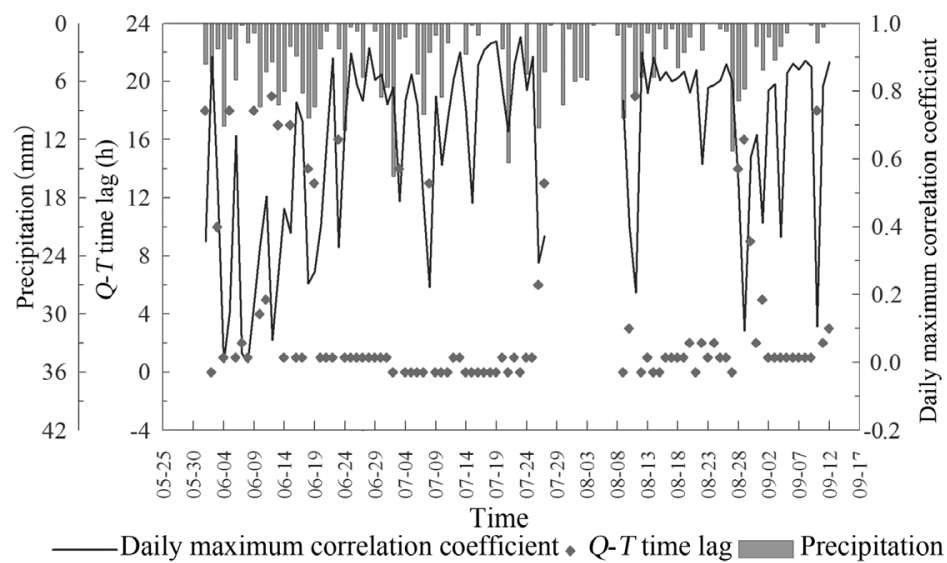

Figure 5 The variation of daily time-lag between discharge and air temperature and daily maximum correlation coefficient at Glacier No.1 gauging station during the ablation season in 2011

\subsubsection{Snowmelt runoff}

Snowmelt runoff refers to the runoff recorded at Empty Cirque gauging station. The melting time at Empty Cirque started later than at Glacier No.1 due to its higher altitude. Although some studies have shown that runoff recorded at Empty Cirque is largely dependent on summer precipitation (Han et al., 2005; Sun et al., 2012b), the fact that $80 \%$ of all precipitation in the Urumqi River source region was solid precipitation in the period from May to September, according to $\mathrm{T}-200 \mathrm{~B}$ rain gauge (Geonor, Oslo, Norway) records, suggested that air temperature also had an important role. Most precipitation was received in May, August, and September in 2011 according to the meteorological data at Empty Cirque gauging station. The duration of snow cover extended into June and July according to snow gauges A-E on April 23, 2011 (Figure 6). The average thickness of the snow cover reached a maxi-

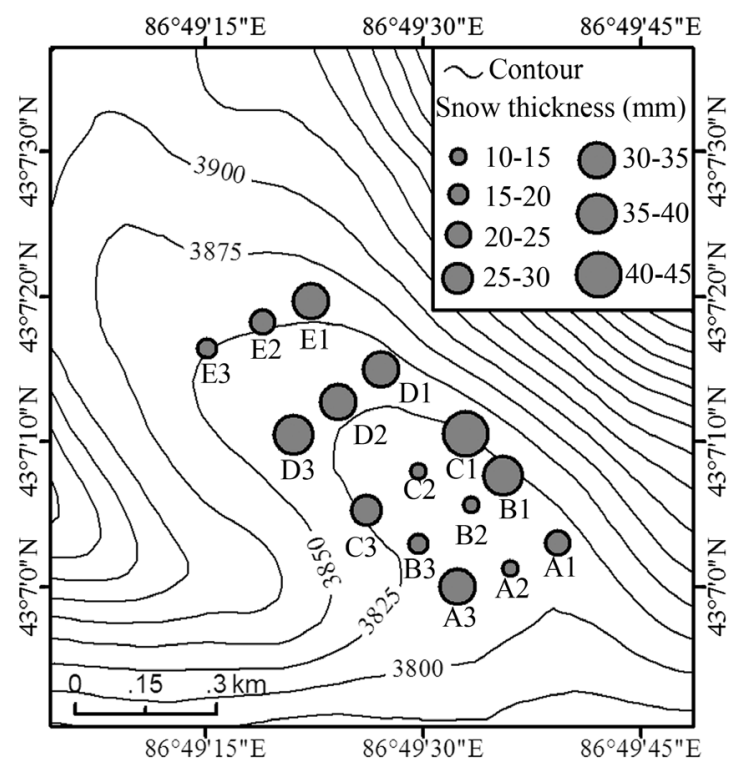

Figure 6 The spatial distribution of snow thickness in the Empty Cirque area on April 23, 2011 
mum in mid-April, with the thickness on both sides of the cirque being greater than in the central area. Therefore, when precipitation was not considered, the discharge curve for Empty Cirque gauging station displayed linear-stage fluctuations that were determined by the diurnal variation of discharge and air temperature on the clear weather days in June and July (Figure 7). This was significantly different from the results recorded at Glacier No.1 gauging station, which may be related to the runoff component of the Empty Cirque gauging station.

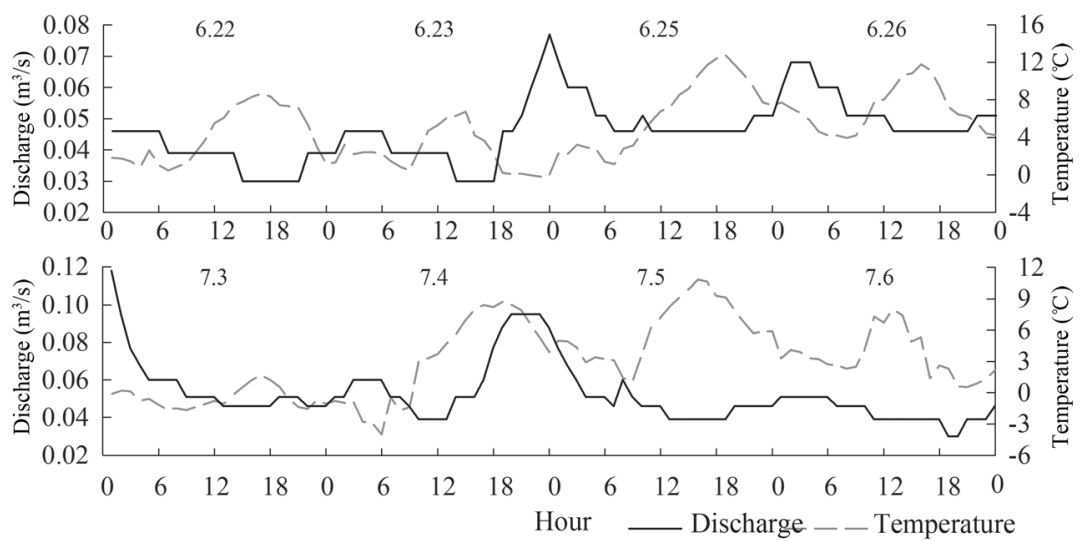

Figure 7 Diurnal variation in discharge (solid line) and temperature (dashed line) of Empty Cirque gauging station in the clear weather days

In the absence of precipitation, the supply of runoff was dependent on the remaining snow melting, because runoff was mainly snowmelt in the Empty Cirque area. Figure 7 shows that the time-lag between the maximum discharge and the highest temperature was 10-16 h, and when precipitation was considered, the time-lag was $\sim 13 \mathrm{~h}$ in the ablation period. The time-lag was more dispersed before the mid-July (Figure 8). The $Q-T$ time lag was larger, which may be related to the water retention capacity of snow cover and talus. In addition, the process from snow cover to melting and runoff generation, and then to confluence again as recorded at the gauging station, indicated that snowmelt runoff and snowmelt did

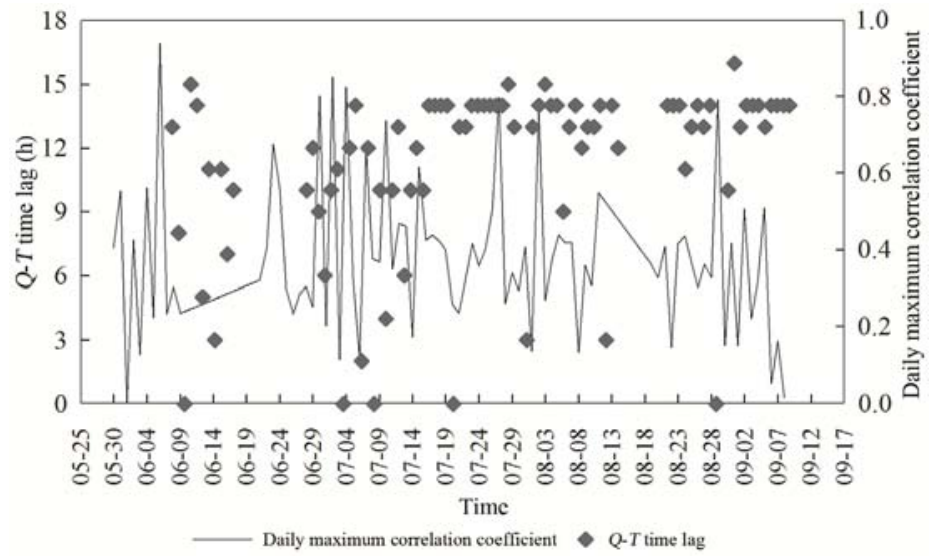

Figure 8 The variation of daily time-lag between discharge and air temperature and daily maximum correlation coefficient at Empty Cirque gauging station during the ablation season in 2011 
not begin at the same time (Singh et al., 2006). We measured snow density and the water content of snow in vertical sections at snow gauges A-E in the Empty Cirque area (Figure 6) using a portable snow fork. The snow density in the Empty Cirque area was $0.05-0.22 \mathrm{~g} / \mathrm{cm}^{3}$, and it was mostly new dry snow. Consequently, snow cover had a marked effect on the accumulation of snow in the Empty Cirque area. It caused the snow melting and recession flow processes to be significantly different, with a delay of half a day or more. The daily maximum correlation coefficient in Figure 8 is small, with an average value less than 0.5 within the study period, which indicates that air temperature is not the main factor controlling the discharge recorded at Empty Cirque gauging station in the ablation period.

\subsubsection{Runoff from the high mountains}

Runoff from the high mountains was recorded at Zongkong gauging station, and included hillside and river-network runoff. Figures 9 and 10 show that the discharge curve of Zongkong gauging station displayed mostly linear variations at the beginning of the ablation period in May. This may be related to a large area of snow melting from 25 to 29 May, when even part of the firn in the glacier area began to melt, although the development of the ablation channel and river system was imperfect. In the absence of continuous precipitation, the runoff supply relied on snow and firn melting; however, they could only melt at high temperatures, and therefore the discharge curve displayed linear-stage variations.

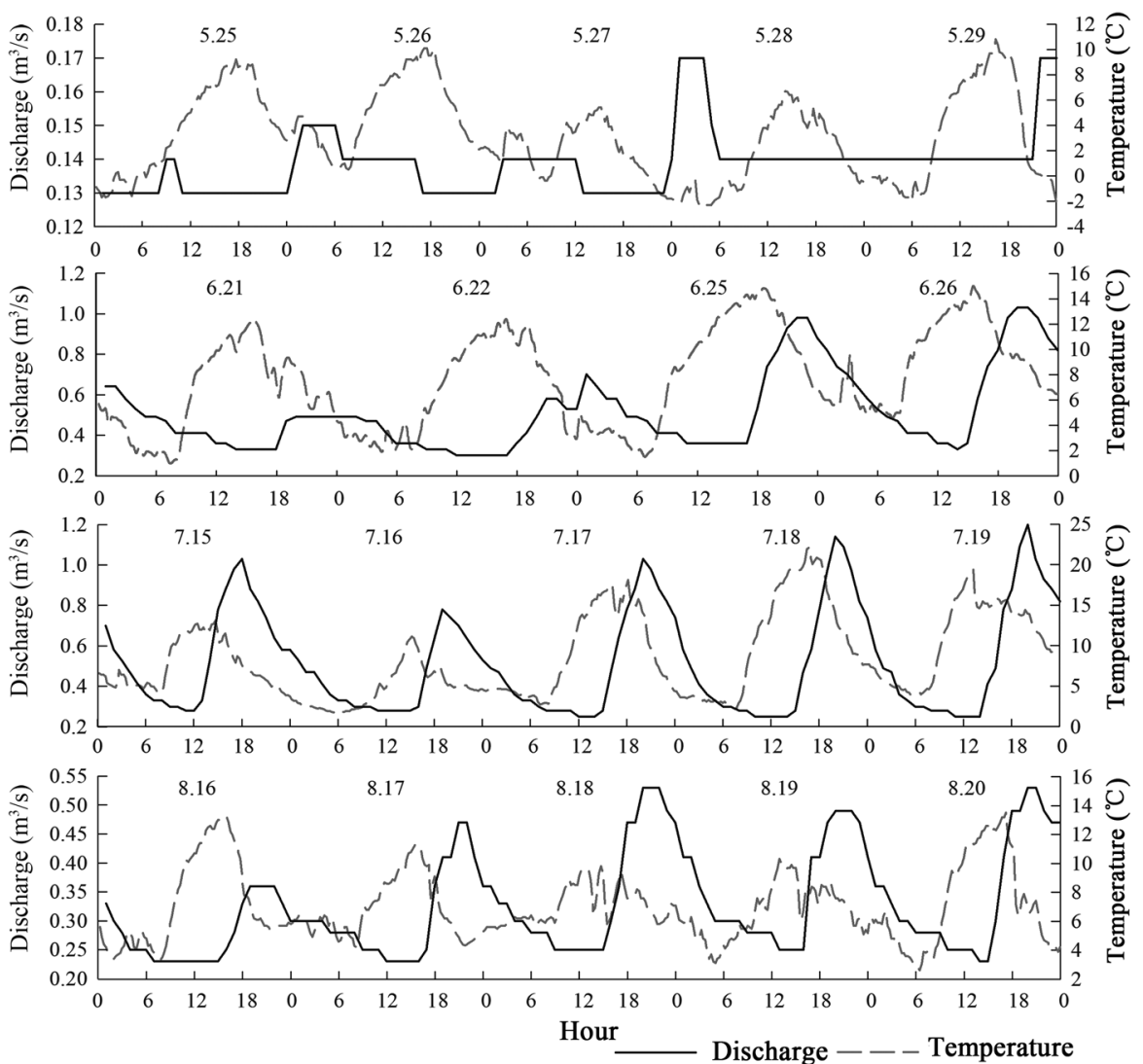

Figure 9 Diurnal variation in discharge (solid line) and temperature (dashed line) of Zongkong gauging station in the clear weather days 


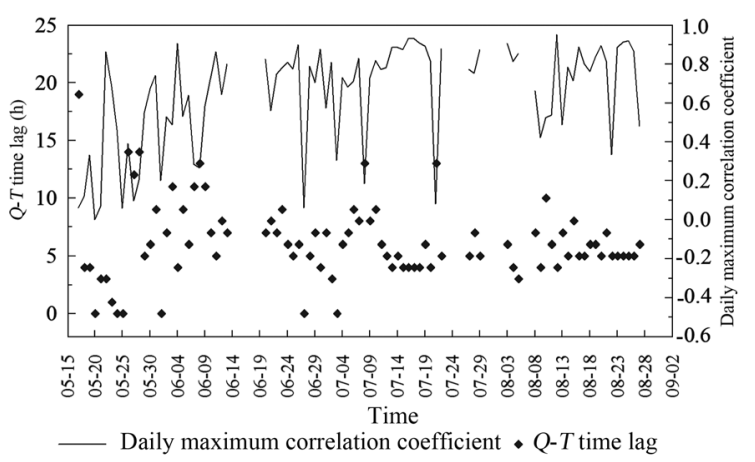

Figure 10 The variation of daily time-lag between discharge and air temperature and daily maximum correlation coefficient at Zongkong gauging station in the ablation season in 2011

When precipitation was not considered, the $Q-T$ lag time was 5-11 h, whereas when it was considered there was a downward trend in the $Q-T$ lag time before June until it eventually stabilized at 6-7 $\mathrm{h}$ in July, which indicated that the $Q-T$ time lag had a decreasing trend with glacier and snow melting. The reason for the changes in the $Q-T$ time lag may be due to there being mostly solid precipitation in the initial stage of melting, causing the area of snow cover to become larger and the albedo to increase. As a result, the glacier melting strength and the meltwater velocity were small, which led to a longer time-lag between the maximum discharge and the highest temperature. The area of snow coverage and the albedo decreased, while the area of bare glacier, the glacier melting strength, discharge, and velocity increased along with a rapid rise in temperature. This led to a more perfect drainage system and a shorter time-lag.

\section{Discussion}

\subsection{Comparisons of the runoff generation and confluence processes at three gauging stations}

By comparing the Q-T time lag at the three gauging stations, with and without consideration of precipitation, it was shown that the conflux speed increased and the confluence time shortened when precipitation occurred. The form of precipitation had a large influence on the runoff characteristics. When precipitation was liquid it rapidly became runoff on the glacier surface, and also accelerated glacier melting and the meltwater velocity, rather than shortening the confluence time. While precipitation was solid, snow days were often accompanied by lower air temperatures. The resulting increase in surface albedo reduced glacier melting, and consequently decreased the meltwater velocity and lengthened the confluence time. The next day, as the weather cleared and temperature rose, a lot of the new snow melted. The increased melting and flow velocity shortened the confluence time. In addition, the variation of the $Q-T$ time lag also reflected the evolution of the underlying surface drainage system at the Glacier No.1 and Zongkong gauging stations. Both stations had a slow drainage system at the beginning of the ablation period that increased in the middle of the ablation period, before decreasing again at the end of the ablation period.

The significant differences in the discharge curves and the $Q-T$ time lag among the three gauging stations indicated that the processes of runoff generation and confluence differed. 
This was related to glacier coverage, with coverage at the Glacier No.1 gauging station of around $50 \%$ and close to $20 \%$ at Zongkong gauging station. The discharge curve at the two gauging stations displayed linear-stage fluctuations in May and September, but was relatively smooth for 6-8 months. These variations reflected the fact that the drainage system did not develop at the beginning and end of the ablation period when glacier melting was limited and the runoff supply was discontinuous. In the strong ablation period, a perfect drainage system developed, with considerable firn and ice melting, which resulted in a continuous runoff supply. The discharge curve for the Empty Cirque gauging station displayed a wide range of linear-stage fluctuations in the middle of the ablation period for 6-7 months. Although the areas of the drainage basin of the Glacier No.1 and Empty Cirque gauging stations were identical, the runoff supply at the Empty Cirque gauging station relied solely on snow melting because it had no glacier coverage. According to studies of glacier and snow melting degree-day factors, and melting data reported for Glacier No.1, the melting degree-day factors of glacier ice are greater than firn and new snow (Cui et al., 2010). Therefore, the melting at Glacier No.1 was far greater than that of Empty Cirque at the same temperature, and thus the discharge curve at the Glacier No.1 gauging station rose and fell steeply, while at Empty Cirque the discharge curve changed more slowly. This demonstrated that the discharge curve and the time-lag between the maximum discharge and the highest temperature could be used to explain the evolution of the drainage system, and the process of glacier and snow melting at different levels of glacier coverage.

Figure 11 shows the fitting curves between discharge and precipitation or temperature at
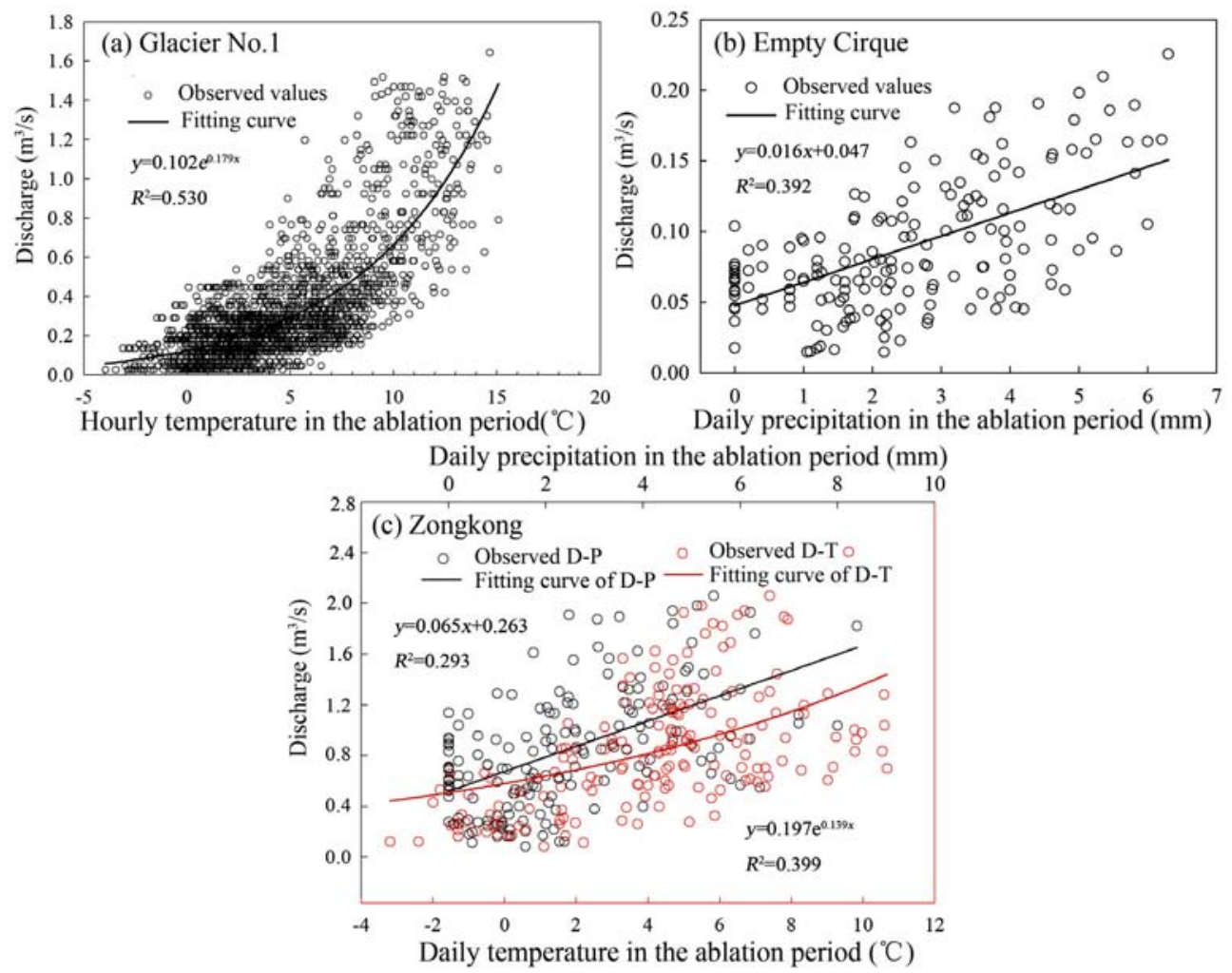

Figure 11 Relationships between discharge and precipitation and temperature at the three gauging stations in the ablation period of 2011 
the three gauging stations in the ablation period of 2011, at two time scales. On an hourly time scale, the discharge at the Glacier No.1 station and the temperature had a significant exponential relationship, where the change in discharge was controlled mainly by heat conditions in the glacierized area and the discharge displayed an accelerated growth when the temperature in the melt season exceeded $5^{\circ} \mathrm{C}$. On a daily time scale, there was a good positive correlation between the discharge recorded at the Empty Cirque station and the precipitation, which indicated that precipitation was the fundamental source of bare hillside runoff. The relationship between discharge and precipitation or temperature at Zongkong station was more complex, and displayed characteristics of both the Glacier No.1 and Empty Cirque stations. On a daily time scale, there was also a positive correlation between discharge and precipitation or temperature, but the degree of correlation was not as good as for the other two stations, which further reflected the fact that water and heat together affect alpine runoff.

\subsection{Comparison of runoff characteristics between Glacier No.1 and some selected representative glaciers}

A comparison of runoff characteristics between Glacier No.1 and six other representative glaciers is shown in Table 2, and indicates differences in the time at which the maximum and minimum discharge appeared, as well as the duration between the maximum discharge and the highest temperature at the six glaciers. Additionally, the $Q-T$ time lag for all the six glaciers was larger than for Glacier No.1. Of the six glaciers, only Qiyi Glacier had similar melting and runoff characteristics to Glacier No.1, with a maximum discharge appearing at 17:00 and a $Q-T$ time lag of $2 \mathrm{~h}$. Although the Koxkar and Rongbuk glaciers were continental glaciers, the scale of both was much larger than Glacier No.1; therefore, the time-lag between the maximum discharge and the highest temperature was longer (4-10 h and 9-14 h, respectively). Rongbuk glacier, on the northern slope of Mount Qomolangma, was the largest glacier selected, with an area of $203 \mathrm{~km}^{2}$ and glacier coverage of $68 \%$. At Rongbuk glacier the delay in the time between the maximum discharge and the highest temperature was the longest of all six glaciers, with the maximum and minimum discharge appearing at 24:00-01:00 and 12:00-15:00 respectively, which indicated that its water retention capacity was significantly greater than that of Glacier No.1. When comparing Hailuogou and

Table 2 The comparisons of glacier melt-runoff characteristics among seven glaciers

\begin{tabular}{|c|c|c|c|c|c|c|c|}
\hline Glacier & $\begin{array}{c}\text { Glacier } \\
\text { area } \\
\left(\mathrm{km}^{2}\right)\end{array}$ & $\begin{array}{l}\text { Distance from } \\
\text { gauging site } \\
\text { to the snout of } \\
\text { glacier }(\mathrm{m})\end{array}$ & $\begin{array}{l}Q-T \\
\text { time } \\
\text { lag } \\
\text { (h) }\end{array}$ & $\begin{array}{l}\text { Maximum } \\
\text { discharge } \\
\text { occurrence } \\
\text { time }\end{array}$ & $\begin{array}{l}\text { Minimum } \\
\text { discharge } \\
\text { occurrence } \\
\text { time }\end{array}$ & $\begin{array}{l}\text { Observation } \\
\text { time }\end{array}$ & References \\
\hline Hailuogou & 25.71 & 500 & $4-12$ & & & 2003-2005 & $\begin{array}{l}\text { Liu and Liu, } \\
2009\end{array}$ \\
\hline Rongbuk & 203.00 & $\begin{array}{l}\text { Near the snout } \\
\text { of glacier }\end{array}$ & $9-14$ & $24: 00-01: 00$ & $12: 00-15: 00$ & 2005.06 & Liu et al., 2010 \\
\hline Koxkar & 83.56 & $\begin{array}{l}\text { Near the snout } \\
\text { of glacier }\end{array}$ & $4-10$ & $18: 00-02: 00$ & 07:00-10:00 & 2000-2003 & Han et al., 2009 \\
\hline Qiyi & 2.87 & $\begin{array}{l}\text { Near the snout } \\
\text { of glacier }\end{array}$ & 2 & $17: 00$ & & 2006.08-09 & Song et al., 2008 \\
\hline Gangotri & 286.00 & 3000 & $4-7.3$ & $17: 00-21: 00$ & 08:00-09:00 & 2000-2003 & Singh et al., 2006 \\
\hline Baounet & 2.50 & $\begin{array}{l}\text { Near the snout } \\
\text { of glacier }\end{array}$ & $2-9$ & & & 2003-2004 & $\begin{array}{l}\text { Jobard and } \\
\text { Dzikowski, } 2006\end{array}$ \\
\hline
\end{tabular}


Gangotri glaciers, which are both maritime-type glaciers, the Gangotri glacier $Q-T$ time lag was shorter. Because Gangotri glacier is located on the southern slope of the Himalayas, with abundant annual precipitation and the well developed subglacial drainage channel; therefore, the melting runoff confluence time was shorter. This analysis indicated that the melting of a glacier and its water yield are complex and closely related to glacier type, scale, regional climate, and the distance of the glacier terminus to the hydrologic section.

\section{Conclusions}

(1) In the Urumqi River source region, the discharge differed markedly among the three gauging stations. The daily discharge was more than the nighttime discharge at the Glacier No.1 gauging station, which contrasted with the results for the Zongkong and Empty Cirque gauging stations. The discharge at all three gauging stations displayed a clear daily variation, with different magnitudes and durations of peak discharge. The timing of the maximum discharge was 14:00-18:00, 23:00-01:00, 21:00-01:00, at Glacier No.1, Empty Cirque, and Zongkong gauging stations, respectively. The timing of the minimum discharge appeared at 08:00-10:00, 13:00-15:00, and 13:00-18:00. The discharge peak was higher and occurred early in the middle of ablation period at Glacier No.1 and Empty Cirque station, but it occurred at the beginning and end of the ablation period at Zongkong station.

(2) When precipitation was not considered, the time-lags between the maximum discharge and the highest temperature were 1-3 h, 10-16 h, and 5-11 h at the Glacier No.1, Empty Cirque, and Zongkong gauging stations, respectively. If the precipitation was considered, their corresponding time-lags were $0-1 \mathrm{~h}, 13 \mathrm{~h}$, and $6-7 \mathrm{~h}$. Therefore, the duration from the discharge generation to confluence was the shortest in Glacier No.1, the second shortest was in Zongkong, and the longest was in Empty Cirque. This showed that the hydrological process from generation to confluence became shorter when precipitation was considered.

(3) It was also demonstrated that the discharge curve and the time-lag between the maximum discharge and the highest temperature could be used to explain the evolution of the drainage system, and the process of glacier and snow melting at different levels of glacier coverage. By comparison, it was found that the englacial and subglacial drainage channel of Glacier No.1 has become simpler during the past 20 years. The weaker retardance and storage of glacier melt water resulted in a rapid discharge confluence. Compared with six other glaciers, only the melting and runoff characteristics of Qiyi Glacier were similar to those of Glacier No.1, which indicated that runoff characteristics are not only related to hydrothermal conditions but are also closely related to the glacier type, scale, and other factors.

(4) The factors influencing the changes in discharge of the three gauging stations were different. For the Glacier No.1 station, the changes in discharge were controlled mainly by temperature conditions in the glacierized region, and the discharge displayed an accelerated growth when the temperature in the melt season was higher than $5^{\circ} \mathrm{C}$. For the Empty Cirque station, the change in discharge was controlled mainly by precipitation. There was a complex relationship between discharge and temperature/precipitation at the Zongkong station, which not only displayed the exponential discharge-temperature relationship of the Glacier No.1 station but also the linear discharge-precipitation relationship of the Empty Cirque station. However, the correlation was less marked than at the other two stations, which may be related to the area of glacier coverage at Zongkong station being smaller than at the other stations. 


\section{References}

Cui Yuhuan, Ye Baisheng, Wang Jie et al., 2010. Analysis of the spatial-temporal variation of the positive degree-day factors on the Glacier No.1 at the headwaters of the Urumqi River. Journal of Glaciology and Geocryology, 32(2): 265-274. (in Chinese)

Fountain A G, Walder J S, 1998. Water flow through temperate glaciers. Reviews of Geophysics, 36: $299-328$.

Gao Mingjie, Han Tianding, Ye Baisheng et al., 2013. Characteristics of melt water discharge in the Glacier No.1 basin, headwater of Urumqi River. Journal of Hydrology, 489: 180-188.

Han Haidong, Liu Shiyin, Wang Jian et al., 2009. Glacial runoff characteristics of the Koxkar Glacier, Tuomuer-Khan Tengri Mountain Ranges, China. Environmental Earth Sciences, 61(4): 665-674.

Han Tianding, Ding Yongjian, Jiao Keqin et al., 2005. Analysis of the extremum of snow and glacier meltwater runoff at the headwaters of the Urumqi River. Journal of Glaciology and Geocryology, 27(2): 276-281. (in Chinese)

Hasnain S I, Jose P G, Ahmad S et al., 2001. Character of the subglacial drainage system in the ablation area of Dokriani glacier, India, as revealed by dye-tracer studies. Journal of Hydrology, 248: 216-223.

Hock R, 2005. Glacier melt: A review on processes and their modeling. Progress in Physical Geography, 29(3): 362-391.

Hock R, Hooke R L, 1993. Evolution of the internal drainage system in the lower part of the ablation area of Storglaciaren, Sweden. Geological Society of America Bulletin, 105(4): 537-546.

Jobard S, Dzikowski M, 2006. Evolution of glacial flow and drainage during the ablation season. Journal of Hydrology, 330: 663-671.

Kang Ersi, 1991. A preliminary study on the drainage system in the ablation area of the Glacier No.1 at the source of Urumqi River. Journal of Glaciology and Geocryology, 13(3): 219-228. (in Chinese)

Kaser G, Großhauser M, Marzeion B, 2010. Contribution potential of glaciers to water availability in different climate regimes. PNAS, doi:10.1073/pnas.1008162197.

Li Zhongqin, Li Huilin, Chen Yaning, 2011. Mechanisms and simulation of accelerated shrinkage of continental glaciers: A case study of Urumqi Glacier No.1 in eastern Tianshan, Central Asia. Journal of Earth Science, 22(4): 423-430.

Liu Qiao, Liu Shiyin, 2009. Seasonal evolution of englacial and subglacial drainage system of temperate glacier revealed by hydrological analysis. Journal of Glaciology and Geocryology, 31(5): 857-864. (in Chinese)

Liu Qiao, Liu Shiyin, 2012. Tracer tests of englacial and subglacial drainage system evolution and a case study at the Hailuogou glacier. Journal of Glaciology and Geocryology, 34(5): 1206-1219. (in Chinese)

Liu Weigang, Ren Jiawen, Qin Xiang et al., 2010. hydrological characteristics of the runoff yield and runoff confluence in the Rongbuk Glacier catchment in Mt. Qomolangma, central Himalayas, China. Journal of Glaciology and Geocryology, 32(2): 367-372. (in Chinese)

Schuler T, Fischer U H, Gudmundsson G H, 2004. Diurnal variability of subglacial drainage conditions as revealed by tracer experiments. Journal of Geophysical Research, 109, F02008, doi: 10.1029/2003JF000082.

Singh P, Haritashya U K, Kumar N et al., 2006. Hydrological characteristics of the Gangotri Glacier, central Himalayas, India. Journal of Hydrology, 327: 55-67.

Song Gaoju, Wang Ninglian, Chen Liang et al., 2008. Analysis of the recent features of the meltwater runoff from the Qiyi Glacier, Qilian Mountains. Journal of Glaciology and Geocryology, 30(2): 321-328. (in Chinese)

Sun Meiping, Li Zhongqin, Yao Xiaojun et al., 2012a. Analysis on runoff variation of Glacier No.1 at the headwaters of Urumqi River from 1959 to 2008. Journal of Natural Resources, 27(3): 650-660. (in Chinese)

Sun Meiping, Li Zhongqin, Yao Xiaojun et al., 2012b. Runoff variation and mechanism at headwaters of Urumqi River in recent 50 years. Arid Land Geography, 35(3): 430-437. (in Chinese)

Sun Meiping, Li Zhongqin, Yao Xiaojun et al., 2013. Rapid shrinkage and hydrological response of a typical continental glacier in the arid region of northwest China: Taking Urumqi Glacier No.1 as an example. Ecohydrology, 6(6): 909-916.

Takeuchi N, Li Zhongqin, 2008. Characteristics of surface dust on Urumqi Glacier No.1 in the Tien Shan Mountains, China. Arctic, Antarctic, and Alpine Research, 40(4): 744-750.

Tianshan Glaciological Station, 2008. Annual Report of Tianshan Glaciological Station (vol.18). Lanzhou: Tianshan Glaciological Station. (in Chinese)

Tianshan Glaciological Station, Lanzhou Institute of Glaciology and Geocryology, CAS; Runoff Experimental Station, Hydrological Bureau of Xinjiang Uygur Autonomous Region, Research Team of Water Resources in Urumqi Region, 1992. Formation and Estimation of Mountain Water Resources in the Urumqi River Basin. Beijing: Science Press. (in Chinese)

$\mathrm{Xu}$ Hui, Li Zhongqin, Takeuchi $\mathrm{N}$ et al., 2013. Characteristics and formation analysis of the cryoconite granules: Take the Urumqi Glacier No.1 as an example. Journal of Glaciology and Geocryology, 35(5): 1118-1125. (in Chinese)

Yang Zhenniang, Liu Xinren, Zeng Qunzhu et al., 2000. China Cold Regions Hydrology. Beijing: Science Press. (in Chinese)

Yin Z L, Xiao H L, Zou S B, 2014. Simulation of hydrological processes of mountainous watersheds in inland river basins: Taking the Heihe Mainstream River as an example. Journal of Arid Land, 6(1): 16-26.

Zhang Yong, Liu Shiyin, Ding Yongjian, 2007. Glacier meltwater and runoff modelling, KeqicarBaqi Glacier, southwestern Tien Shan, China. Journal of Glaciology, 53(180): 91-98. 